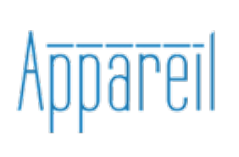

Appareil

$22 \mid 2020$

Une philosophie de l'appareil

\title{
Merci Jean-Louis
}

\section{Caroline Coppey}

\section{(2) OpenEdition}

Journals

Édition électronique

URL : http://journals.openedition.org/appareil/3532

DOI : 10.4000/appareil.3532

ISSN : 2101-0714

Éditeur

MSH Paris Nord

\section{Référence électronique}

Caroline Coppey, «Merci Jean-Louis », Appareil [En ligne], 22 | 2020, mis en ligne le 21 décembre 2020, consulté le 26 mars 2021. URL : http://journals.openedition.org/appareil/3532 ; DOI : https://doi.org/ 10.4000/appareil.3532

Ce document a été généré automatiquement le 26 mars 2021.

\section{(c) (i) (2) $\Theta$}

Appareil est mis à disposition selon les termes de la Licence Creative Commons Attribution - Pas d'Utilisation Commerciale - Pas de Modification 4.0 International. 


\section{Merci Jean-Louis}

\section{Caroline Coppey}

En hommage à Jean-Louis Déotte, le texte extrait de l'un de ses derniers écrits inachevés (Figure 1) a été exposé dans l'exposition personnelle intitulée Résonance de la couleur que j'ai présentée en 2018 à La Pharmacie, centre culturel de l'hôpital du Tonnerrois. Originaire par son père de cette région Bourgogne, Jean-Louis rêvait depuis sa prime jeunesse de voir l'hôtel-Dieu de Tonnerre retrouver une nouvelle vie en accueillant l'art le plus contemporain. Il a ainsi contribué tout d'abord à l'émergence, puis à la direction artistique de ce nouveau lieu d'exposition. L'exposition Résonance de la couleur a été conçue, avec Frédéric Roussel et toute l'équipe de La Pharmacie, comme un hommage rendu à Jean-Louis, qui suivit mon cheminement artistique depuis ses débuts. La Froissée $n^{\circ} 19$ (Figure 2) a été réalisée en sa mémoire. L'installation in situ de 1408 Papiers de couleurs uniques (Figure 3), en mettant en évidence la résonance vibratoire de la couleur dans l'espace, nous invitait à une immersion sensible dans ses champs colorés, générant un "espace immersif » et illustrant par là un concept développé par Jean-Louis dans le cadre de l'esthétique contemporaine. 
Figure 1 : Extrait de l'exposition « Prendre soin » comme déniaisement

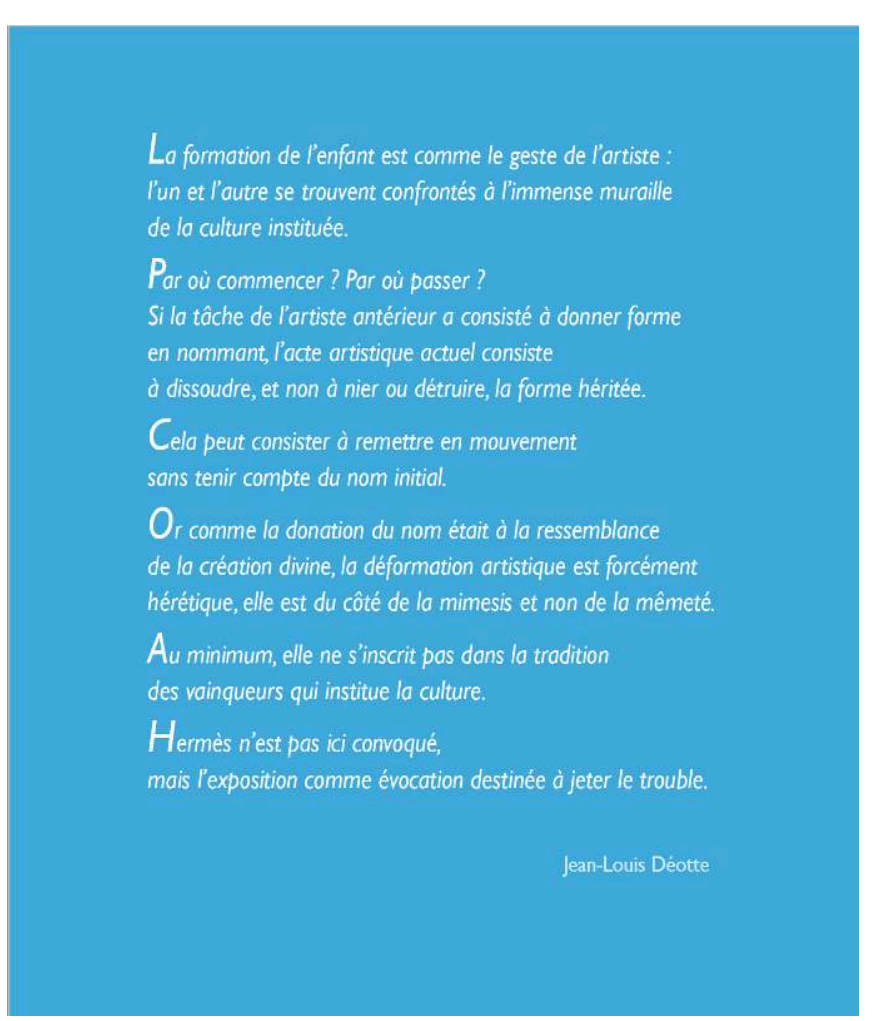

Panneau @ Jean-Louis Déotte, Extrait de l'exposition «Prendre soin » comme déniaisement, 2017 Panneau présenté dans l'exposition Résonance de la couleur réalisée en hommage à JeanLouis Déotte, à La Pharmacie, espace culturel du centre hospitalier du Tonnerrois, du 30 juin au 4 novembre 2018 (crédits image : Jean-Louis Déotte, 2017) 
Figure 2 : Froissée $n^{\circ} 19$

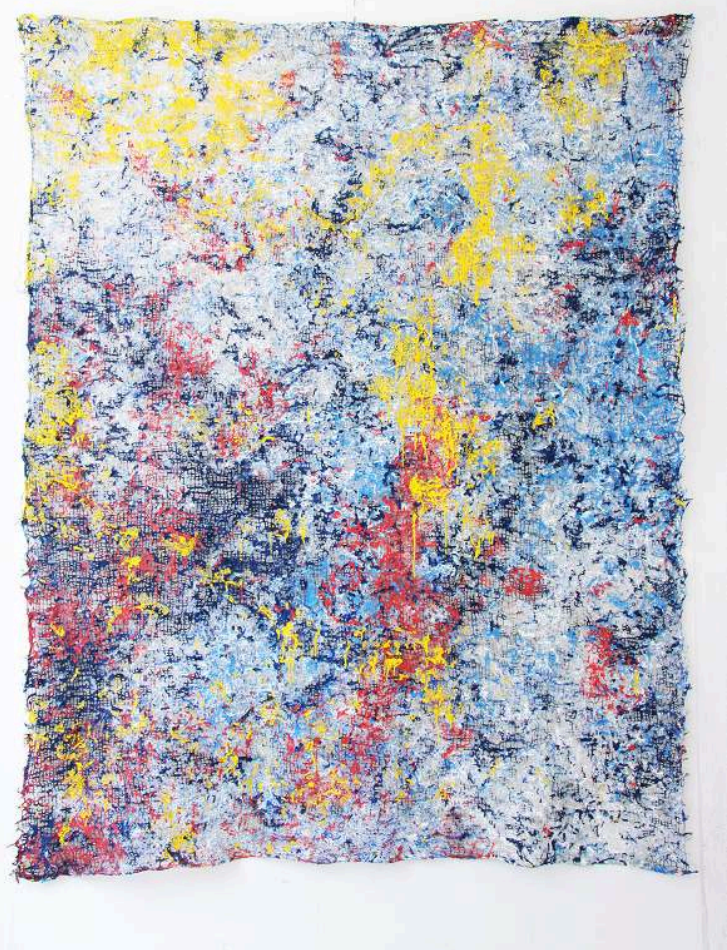

Tableau ( C Caroline Coppey, Froissée $n^{\circ} 19,2018,220 \times 165 \mathrm{~cm}$, huile et acrylique sur toile, œuvre présentée dans l'exposition Résonance de la couleur (crédits image : Caroline Coppey, 2018)

Figure 3 : 1408 Papiers de couleurs uniques

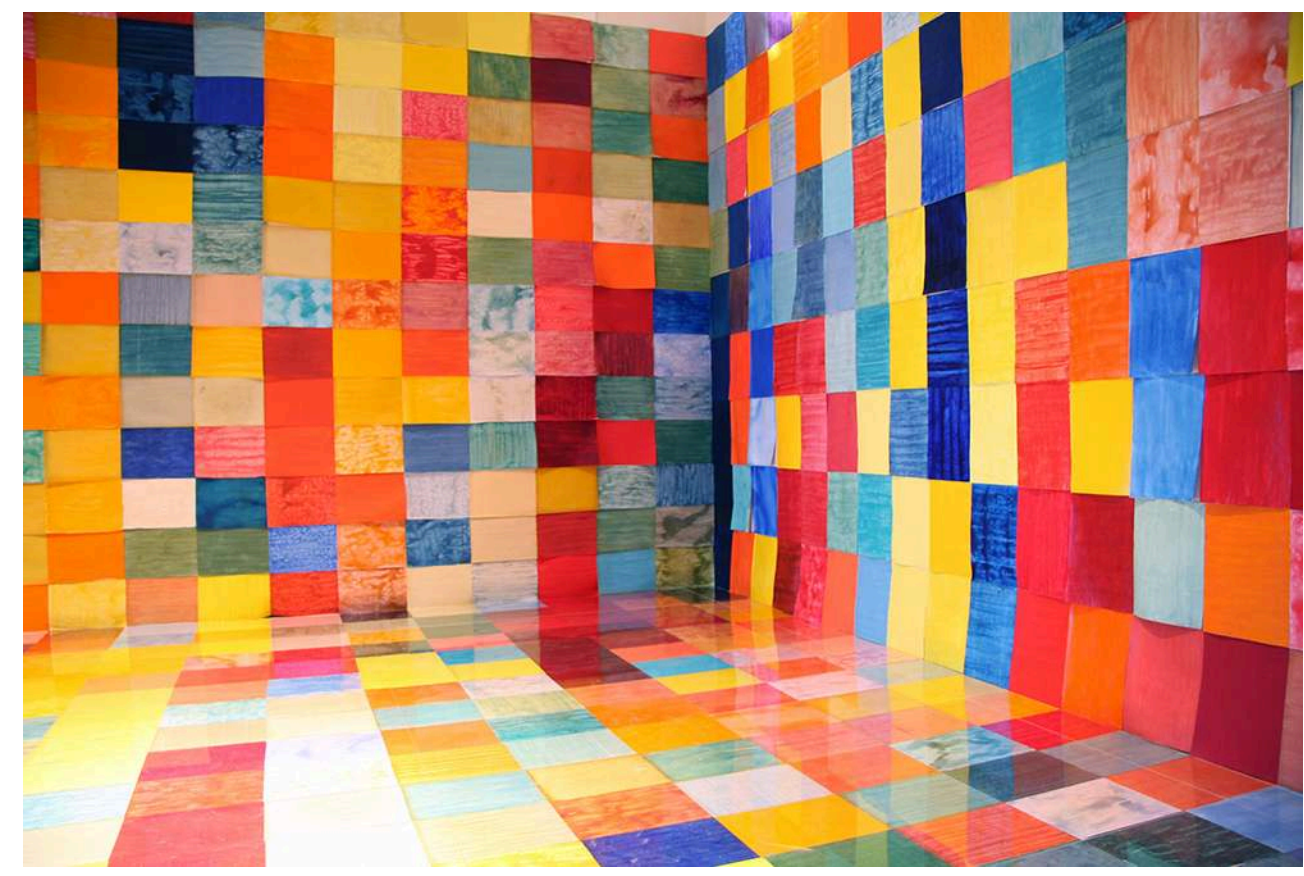

Installation (c) Caroline Coppey, 1408 Papiers de couleurs uniques, $1408 \times(21 \times 29$ cm), 2007-2018, huile et acrylique sur papier, installation in situ présentée dans l'exposition Résonance de la couleur (crédits image : Caroline Coppey, 2018) 


\section{AUTEURS}

\section{CAROLINE COPPEY}

Artiste, auteur de la thèse de doctorat «Claude Monet : À l'école de l'œil » publiée en 2013 dans la collection Esthétiques de l'Harmattan, avec une préface de Jean-Louis Déotte ; www.carolinecoppey.com, info@caroline-coppey.com 